and Pinner, of New York), lithium polyphosphate (Saini, of Turin), polymethacrylic acid (Kryszewski, of Torun, Poland), sodium alginate (Allgen, of Stockholm) and the sulphate of aminoacetalized polyvinyl alcohol (Matsumoto, of Okayama). The electroviscous effect shown by rigid polyelectrolytes (Donnet, of Mulhouse), the interaction of ionized polyelectrolytes with polarized mercury-water interfaces (Miller, of Rehovot) and the potentiometry of polyelectrolyte gels (Michaeli and A. Katchalsky, of Rehovot) were also discussed. The unequal permeability to different ions of hydrophilic membranes impregnated with polyelectrolytes, particularly the copper ferrocyanide and sulphuric acid/'Cellophane'/barium hydroxide membranes, was studied by Hirsch-Ayalon (Utrecht).

In the field of protein and polypeptide chemistry, two papers on the surface chemistry of synthetic polypeptides (Isemura, of Osaka) and gliadin and zein (Jaffe, of Brussels) were presented. The deuterium exchange of poly-DL-alanine with water suggests that it exists in aqueous solution in a folded, possibly helical form (Berger and Linderström-Lang, of Copenhagen), while a reversible transformation between helix and random coil has been found for solutions of poly-L-glutamic acid (Doty, of Harvard; Blout, of Boston). A general review of the solution behaviour of poly- $\alpha$-amino-acids was given by F. Katchalsky (Rehovot), and the reversible heat coagulation of some of these was described by Noguchi (Kanazawa). Polybases (for example, polylysine) agglutinate red blood cells, altering their surface potentials (Nevo, de Vries and A. Katchalsky, of Israel), Meyer (New York) reviewed recent developments in our knowledge of the structure of connective tissue, and other proteins investigated were bovine serum albumin (Champagne, of Strasbourg) and actomyosin (Wassermann, of London).

Nucleic acids were also discussed in several papers and in two lectures by Jordan (Adelaide) and Watson (Cambridge, Mass.). These polymers have been investigated by a variety of physico-chemical techniques: for example, the ultra-centrifuge (Shooter and Butler, of London ; Desreux, of Liège), lightscattering (Pouyet and Weill, of Strasbourg), streaming birefringence (Wahl, of Paris ; Mathieson, of Nottingham), electrophoresis (Mathieson) and titration (Peacocke, of Birmingham; Mathieson).

Carbohydrates also received some attention. In a most interesting paper, Usmanov (Tashkent) discussed the physico-chemical behaviour of native cellulose and showed that the molecular weight increases steadily as the cotton fibre becomes older, so that the biosynthesis of cotton is apparently a polycondensation process. Spectroscopic studies of the ageing of starch were described by Samec (Ljubljana), while other carbohydrates investigated were levan, a polymer of $\mathbf{D}$-fructose (Feingold and Gehatia, of Israel) and the cycloglucans (Freudenberg, of Heidelberg). Although cupriethylene diamine and cuprammonium hydroxide can be used as solvents in the molecular fractionation of cellulose, they are not recommended because of the degradation that may occur (Sihtola, of Helsinki). Theoretical aspects of polydispersity were considered by Hultin (Stockholm) and Daune (Strasbourg). The swelling of regenerated cellulose (Nowakowski, of Lodz), the sorption and diffusion of organic vapours by ethyl cellulose (Barrer and Barrie, of London) and adsorption on glass-like polymers (Kargin, of Moscow) were also investigated. The flexibility in solution of molecules of hyaluronic acid was reported by Rowen (Los Angeles).

Miscellaneous studies on vinyl polymers included the effect of branching on the solution properties of polyethylene (Trementozzi, of Springfield, Mass. ; Mussa, of Turin), the irradiation of polymers in solution (Charlesby and Alexander, of England), the swelling of graft copolymers of acrylonitrile on polyethylene (Chapiro, of Paris) and the preparation of various graft copolymers (Mesrobian, of Brooklyn). Finally, the preparation and properties of several nitrogen-containing polymers were described: for example, polyaminocarboxylic acids and polyvinylamides (Smets, of Louvain) and poly-N-vinylpyrrolidone (Breitenbach, of Vienna).

It is to be hoped that this highly compressed survey gives some idea of the tremendous variety of topics discussed. This catholicity was deliberate, as one of the objects of the organizers was to bring together workers on biocolloids and synthetic polymers so that cross-fertilization of ideas could take place. Judging by the animated discussions that took place inside and, to an even greater extent, outside the lecture halls, this aim was fulfilled. All the papers, together with the discussions, will be printed in full in a special issue of the Journal of Polymer Science.

L. Valentine

\section{PROGRESS IN THE STUDY OF THE BRITISH FLORA}

$\mathrm{K}$ NOWLEDGE of the British flora has advanced during the past decade at a rate which has never been equalled before. New techniques and a fresh approach to old problems have resulted in rapidly increasing progress, and the present is therefore an appropriate time for review of old and new methods with the object of suggesting the most fruitful lines for future development. This was the purpose of the conference arranged by the Botanical Society of the British Isles under the title of "Progress in the Study of the British Flora", which was held in Bedford College, London, during April 13-14.

The conference was opened by Prof. T. G. Tutin (University College, Leicester), who directed attention to the importance of learning to regard the flora of the British Isles as a small part of that of Europe. The insularity of British workers has not yet been entirely broken down, and a wider view can have important consequences for the future progress in the study of the British flora. To know their flora properly, British workers must enlarge their scope, and a start in this direction has already been made by experimental taxonomists and specialists in certain genera. Prof. Tutin suggested that the Society could play a valuable part in helping workers to take this wider view, and this proposal was enthusiastically supported by later speakers.

Most of the first day was devoted to consideration of old methods. Canon C. E. Raven discussed "The Early Development of a Knowledge of the British Flora". He pointed out that Witliam Turner, the 'Father' of English botany, had little success in his efforts to identify English plants in the classical botany books until he travelled abroad. As soon as he came across the dried herbaria of Luea Ghini and the admirable pictures in Brunfels, his task became manageable. The discipline which this primary business of nomenclature involved was an exacting, 
and therefore very valuable, preparation for botanical studies : it gave to these early students a power of detailed observation and minute discrimination which has seldom been surpassed. Ray very seldom confused species that we distinguish, or, except when he relied on hearsay evidence, described plants which we cannot easily and accurately name. This primary business of naming, and its sequel in arrangement and classification, gave rise to study of the habitat and of problems of plant structure and physiology, and the seventeenth-century botanists got as far as was possible until the basic sciences emancipated themselves from magic and tradition. During the discussion which followed Canon Raven's paper, attention was directed to the value of these old records as a starting-point for new investigations. It is significant that some. species, such as Veronica spicata in Cambridgeshire, have remained for a period of three centuries in the same localities without extending their range, while others have shown rapid spread in much shorter periods.

The next paper, by Mr. J. E. Lousley, considered "The Contribution of Exchange Clubs to Knowledge of the British Flora". When large-scale organized exchange of herbarium specimens was started in Edinburgh and London in 1836, facilities for studying dried and localized dried material were very limited indeed. For the first twenty years, their efforts were directed towards supplying herbarium specimens in large numbers to meet the need of the time. From 1857 to 1878 there was a transitional period when emphasis passed from mere exchange to the study of critical plants, which was their proper function for the remainder of their history. They provided much of the standard material now available for consultation, and the notes printed in the reports provide a record of the views of contemporary botanists on these specimens. By focusing attention on variation, they brought to notice almost all the segregates which cytology or other modern methods have shown to be of importance, and many hints for useful new work may still be found by examination of old reports and the specimens to which they refer.

Dr. J. G. Dony then followed with a paper on "The Place of the Local Flora in the Study of the British Flora". He suggested that local floras have been largely responsible for making Britain, from the botanical point of view, the best-studied part of the world and have served to collect together information on the behaviour of our plants in addition to detailed data on their distribution. There is hope that a fresh pattern for local floras will emerge from the new methods of study now available. The system of working on the basis of the squares of the National Grid which is being used for the new Cambridgeshire, Derbyshire and Warwickshire Floras shows considerable promise.

Prof. P. W. Richards described the progress of the "Biological Flora" which is appearing in parts as supplements to the Journal of Ecology. Since active work on this project commenced in 1940, accounts of seventy-four species have been published, and about a hundred and sixty more are in preparation ; although contributors work to a schedule, the plan allows for considerable elasticity in the treatment of individual species. Several suggestions for increasing the scope of this very useful work emerged from the discussion which followed. These included a plea for more detailed cytological information, a request for really full descriptions of each species to cover characters omitted for lack of space in most descrip- tive floras, and a suggestion that there is a need for a central office on the lines of the Maps Scheme of the Botanical Society of the British Isles to collect autecological information and give assistance and encouragement to volunteers.

On the second day of the conference all the speakers were concerned with recent developments. Mr. Keith Jones (Welsh Plant Breeding Station, Aberystwyth) directed attention to the importance of current work in cytology in his paper on "Some Aspects of Plant Variation : the Grasses". It is common knowledge that a species is not necessarily characterized by one chromosome number alone, but may embrace forms having two or more different numbers; perhaps it is not so well realized that there can also be pronounced intraspecific variation in chromosome pairing at meiosis. This can give important information about the nature and evolutionary origin of a species. Mr. Jones showed from examples that cytological work on artificially reared seedlings can give very different results from similar work on natural populations of the same species. The experimental taxonomist is concerned with the species as it exists after natural selection has operated, and for this purpose it is necessary to collect plants in the field. Studies based on a few individuals are of limited value, and in all cases it is important that the source of material used for chromosome determinations should always be clearly stated in publications.

"The Importance of Experimental Ecology in the Study of the British Flora" was the subject of a contribution from Dr. F. H. Whitehead (Department of Botany, University of Oxford). He pointed out that descriptive ecology discloses problems and suggests hypotheses which should then be tested by experimental work at various levels of refinement. One of his examples covered recent work at Oxford on two calcifuges, Galium saxatile and Holcus mollis, and two calcicoles, Scabiosa columbaria and Asperula cynanchica. When Scabiosa columbaria was grown in standard water cultures, one with a high $p \mathrm{H}$ and the other with a low $p H$, there was no significant differ. ence in the growth of the plants, and yet when grown from seed in contrasting soils the plants behaved quite differently. These differences were maintained in water cultures prepared from soil adjusted to high and low values of $p \mathrm{H}$. It was concluded that the soil substance affecting growth was water-soluble, and likely to be aluminium. In water cultures with aluminium salts added, Scabiosa columbaria behaved in the same way as in cultures prepared from acid soils and produced a small and malformed root system. Thus, on acid soils containing aluminium this plant would be eliminated at the seedling stage during a period of drought. Although it grows especially on soils with a high $p H$ due to a high proportion of calcium carbonate, it will grow equally well on soils rich in other bases-the effect of calcium carbonate is only secondary in making the aluminium not available to the plant. Very similar results were obtained for Asperula cynanchica. Examples of this kind show that problems are much more complex than has been hitherto believed, and Dr. Whitehead concluded with a plea for more experimental work of an autecological nature.

Dr. F. Rose (Bedford College, London) opened his paper with a similar plea. In considering "The Importance of Relict and Disjunct Distributions in the Interpretation of the History of the Present British Flora", he put forward hypotheses explaining modern distributions in terms of post-glacial historical 
changes with the view of stimulating detailed autecological work on the groups of species he mentioned. Dr. S. M. Walters (Botany School, University of Cambridge) gave a survey of the history of mapping plant distributions. In Britain, H. C. Watson in 1836 published a clear statement of the different possible methods to be adopted - area outline, vicecounty, and dot maps as they later developed-but, apart from Miller Christy's map of the oxlip in 1884, his ideas were not followed up. The first published vice-county maps for the whole of the British Isles appear to be those in Sir Edward Salisbury's "East Anglian Flora" (1932), although county maps had been included in the "Cambridge British Flora" (1914-20). In visual presentation of distribution data, we have made a much later start than other European countries. Dr. Walters suggested that we could repay our debt to European phytogeography by proposing a practical, standardized method to map the European flora, and he exhibited the outline of such a method.

In the last paper delivered to the conference, Prof. D. H. Valentine (University of Durham) considered "The Study of our Flora as Part of a Whole". Using the family Primulaceae as his main example, he demonstrated the importance of looking at the British flora as a constituent part of the boreal flora as a whole, and emphasized the importance of combining cytogenetical and taxonomic investigations. $\mathrm{He}$ urged co-operation with botanists in Europe and the production of a European Flora as outstanding needs.

In addition to the main papers, six exhibitors read short accounts of their exhibits. Mr. A. D. Bradshaw (Department of Agricultural Botany, University College of North Wales, Bangor) described an investigation of the Agrostis population of a very old pasture, Port Meadow, Oxford. The composition of a sample of sixty plants on a morphological basis, confirmed by pollen fertilities, was shown to be $A$. tenuis $1 \frac{1}{2}$ per cent, $A$. stolonifera $3 \frac{1}{2}$ per cent, plants of $F_{1}$ type 70 per cent, and plants not easily ascribable to these categories, presumably $F_{2}$ 's or back-crosses, 25 per cent. The population is therefore composed almost entirely of sterile hybrid plants able to compete successfully with their parents under heavily grazed conditions. Miss M. E. Bradshaw (University of Durham) reviewed the distribution of the segregates of Alchemilla vulgaris aggr. in Britain, Mr. P. A. Gay (University College of Wales, Aberystwyth) discussed the taxonomic status of Erica mackaiana, and Mr. K. M. Goodway (University College of North Staffordshire) the morphological and cytological types of Galium pumilum. Mr. D. M. Moore (University of Durham) considered the status of Viola lactea, and Dr. W. S. Lacey (University College of North Wales, Bangor) described the spread of Galinsoga parviflora and G. ciliata in Britain.

Looking back over the two days of the conference, it is clear that there was general agreement that the most promising lines for furthering our knowledge of the British flora are yet closer collaboration between field and laboratory studies, and greatly increased collaboration with European botanists. It was remarkable how these general proposals kept cropping up in almost every paper and throughout the discussions, and there was enthusiastic support for some of the measures suggested for putting them into practice. The proceedings of the conference will be published by the Botanical Society of the British Isles later this year in a book under the same title.

\section{THE POSITIVE CONTRIBUTION BY IMMIGRANTS}

A SYMPOSIUM, "The Positive Contribution by Immigrants", prepared for the United Nations Educational, Scientific and Cultural Organization by the International Sociological Association and the International Economic Association (pp. 203. Paris : Unesco ; London: H.M.S.O., 1955 ; 600 francs, $12 s .6 d$. or 2.25 dollars), includes five national studies covering the United States, Great Britain, Australia, Brazil and the Argentine Republic. There is also a short survey of the economic aspect, by Brinley Thomas, which details some of the outstanding inventions or industries in the United States attributed to immigrants and suggests that the qualitative contribution of immigrants as a source of outstanding talent and of general man-power is likely to remain a vital factor in economic development. Australian economic life has been much enriched by men of diverse nationalities endowed with varied skills and aptitudes, and in reviewing recent British experience he remarks of science that in no department of human activity is it truer to say that protective barriers are a cause of impoverishment and that their romoval will always redound to the benefit of the community as a whole.

Dealing specifically with Great Britain, Mr. J. Isaac quotes some examples of the wide range of scientific activities which have been influenced by alien immigrants since 1933. Of 533 Fellows of the Royal Society, twenty-one went to Britain as refugees from the Continent of Europe, and many chairs at British universities are held by such immigrants; they have participated in such achievements as the British contribution to the development of nuclear energy, and a particularly noteworthy example is that of Prof. H. A. Krebs and Prof. E. B. Chain, who have shared the Nobel Prize for Medicine. As entrepreneurs and managers, pre-war immigrants have made notable contributions, introducing new ideas or specializing in branches of trade neglected in Britain, and their contribution in the Welsh Development Area in particular has received high praise in Parliament. The contribution of immigrants to the relief of Britain's post-war man-power problems has been limited by the qualified support given by British trade unions, the low standards of medical fitness, education or intelligence used for the selection of the workers, and by difficulties in finding accommodation in Britain for other members of the worker's family. Discussing the demographic aspect, Mr. Isaac points out that it would be a fallacy to assume that Britain could absorb a constant inflow of large numbers of immigrants in the future with similar favourable results, even if suitable persons were available, unless the immigrants could show that they have a special contribution to make.

In a concluding chapter, Mr. Oscar Handlin reviews generally the contributions of immigrants, particularly with reference to the depth of their influence on the host cultures and the extent to which those contributions were determined by the social conditions the immigrants encountered or by the character of the immigrants themselves. Finally, he concludes that, in a larger perspective, immigration establishes a complex of human ties. and linkages that play a significant part in extending international understanding. 